\title{
SABATO/BORGES: SOBRE EL CIELO Y EL INFIERNO
}

POR

\author{
LELIA M. MADRID \\ University of Western Ontario
}

\begin{abstract}
¿Elaborar otra versión sobre el cielo y el infierno? Borges - y Adolfo Bioy Casares - responden con una antología, el Libro del cielo y el infierno. El prólogo es de 1959. En 1966, Ernesto Sábato proponía su propia "historia" del cieloy del infierno". "Sobre la existencia del infierno" es una pieza personal; así, en efecto, lo declara su autor:
\end{abstract}

(L)a teoria ... (s)e me ha ocurrido como consecuencia de algunas experiencias personales y, seguramente, bajo la presión de fuertes obsesiones inconscientes (217).

Más adelante, añade otro comentario de un tenor parecido:

No mencionaré aquí mis experiencias personales que, por serlo, son para mí de enorme e impresionante importancia, pero que para los otros carecen de valor probatorio; debo decir, sin embargo, que son estas experiencias personales, as 1 como el sonambulismo que me aquejo de niño, los que me han empujado hacia el estudio de la parapsicología (217).

\footnotetext{
${ }^{1}$ Se hace referencia a la edicion de Jorge L. Borges y Adolfo Bioy Casares, Libro del cielo $y$ del infierno (Buenos Aires: Sur, 1975).

2 "Sobre la existencia del infierno", fue primeramente publicado en la revista Janus, 6 (Buenos Aires, julio-set. 1966): 91-94 y reimpresa posteriormente en diversos volúmenes de ensayos: La robotizacion del hombre $y$ otros ensayos (Buenos Aires: Centro Editor de América Latina, 1981): 25-31; también en Páginas de Ernesto Sábato (Buenos Aires: Celtia, 1983): 217-222; asimismo, véase la p. 305 de la novela Abaddón el exterminador (Barcelona: Seix Barral, 1978). Se sigue aqui la paginación que se encuentra en el volumen Páginas de ..., antes citado. Véase, respecto del texto en cuestión (y de la contraposición Borges/Sábato), las fuentes que se apuntan en el trabajo de Salvador Bacarisse, "La cosmología gnostica de Sábato: una interpretación de Abaddón el exterminador", en Epica dadora de eternidad. Sabato en la critica americana y europea, ed.A.M. Vázquez Bigi (Buenos Aires: Sudamericana (Planeta, 1985), 195-196 y las notas en p. 216).
} 
Lo que se advierte, además del contexto personalizado del ensayo -algo que podría hacerse extensivo a muchas otras piezas de Sábato-, es la nota que lo ubica dentro de la reflexión ensayística sobre lo inconsciente, en todo caso, lo irracional. Lo que se presenta, en principio, como una teoría sobre la existencia del infierno, se actualiza (y termina) en tanto alabanza de las facultades irracionales, en especial de la imaginación artística y sus virtualidades.

De alguna manera, podría ya anticiparse que si la pieza está enmarcada por la nota personalística, ésta se provee dentro del registro de la reflexión sobre lo irracional. Lo que se advierte en el primer párrafo citado es válido para el segundo caso que se ha mencionado. El ensayo funciona, así, dentro de un doble registro (y esto pareciera estar relacionado con la concepción binaria que lo informa), donde lo personal va unido fuertemente a lo irracional y a la inversa. Uno parece no poder existir sin el otro. De igual manera, lo irracional está presentado aquí en función de (y en oposición a) su contrapartida: la razón crítica. Esta dialéctica de polaridades es constante en un discurso donde lo uno y lo otro aspiran a realizar una síntesis.

El punto de llegada (el punto de convergencia más claro) es el artista y sus facultades, algo que puede afirmarse de muchos ensayos de Sábato. Es a ese punto al que la dialéctica de extremos que informa el discurso de Sábato se dirige: la conciliación de los contrarios por el arte. El proceso discursivo del texto lo muestra en repetidas oportunidades. Así, por ejemplo, la voz narrativa nos informa acerca de un hecho curioso acaecido al pintor surrealista Domínguez - amigo de Sábato-en París, antes de la segunda guerra mundial (de acuerdo con Sábato, pp. 217-218). El resultado (la pérdida del ojo de otro pintor, Brauner, que pareciera haberlo presentido, según Sábato, dada la naturaleza de sus cuadros antes del desgraciado incidente) lleva a la siguiente reflexión ${ }^{3}$ :

Atribuir semejante fenómeno a una suma de coincidencias casuales es sólo deseo de negar la auténtica explicación: el instinto premonitorio del artista, la visión profética que suele caracterizarlo, al menos en instantes excepcionales (218).

Ahora bien, lo premonitorioy susventajas, etc, es el pretexto para hablar de otra cosa, el artista y sus facultades; la premonición cierta, "verdadera", sería una

\footnotetext{
${ }^{3}$ La referencia al incidente tampoco es extraña (o casual) en lo que concierne a la obra de Sábato. La ceguera, como se sabe, constituye una de las más visibles constantes en su escritura. Es posible encontrar algún tipo de relacion entre la ceguera (presente o futura, en este caso) y la persona del artista. En otras palabras, la idea del vate ciego, del que puede ver no a través de los ojos sino por medio de la intuición, etc. Sobre este episodio y sobre la conexión entre Sábato y los surrealistas, véase el artículo de Daniel-Henri Pageaux, "El túnel de Sábato: la trágica correspondencia del arte y la vida", en Epica dadora de eternidad ..., 99-118, sobre todo, 102-109 y notas en 117-118; en el mismo volumen véase también el art. cit. en la nota anterior, sobre todo en 205-206 y 218 (nota 38).
} 
de ellas. Hay otras, por supuesto, y éstas son las que se privilegian en el ensayo antes que la meditación sobre el infierno. Después de reflexionar sobre el alma, dentro de un registro binario que la opone al cuerpo ${ }^{4}$, esto es, a lo que se denomina como físico o material (218-219), se vuelve a la reflexión sobre lo irracional. Se habla sobre las culturas "primitivas" y su concepción del mundo (219), la importancia de la clarividencia que aportan los sueños (220) respecto del pasado y del futuro (en la teoría de Sábato): “¿No podría ser que ciertos sueños venturosos fuesen visiones del Paraíso, asi como ciertas pesadillas visiones del Infierno?" (idem). Hasta aquí la primera parte del ensayo.

La segunda parte se concentra en la visión y la experiencia infernal y/o paradisíaca de los seres "anormales" (videntes, locos, artistas y místicos, en la (220). Los "normales" pueden sólo acceder a esas regiones, según la teoría de Sábato, mediante "esa pequeña muerte transitoria que es el sueño" (221). Lo que resta de esta página hasta el final (esto es, en 221-222), es una reflexión sobre el artista. La ubicación de la misma demuestra implícita y explícitamente que ella es lo privilegiado por el escritor:

[S]6́lo los grandes poetas nos han revelado de verdad su existencia [la del infierno], dándonos visiones detalladas de sus antros. Son nombres terribles e indisputables: Blake, Milton y Dante, Rimbaud y Baudelaire, Lautréamont y Sade, Strindberg y Dostoievsky, Hölderlin y Kafka. ¿Quién osaría poner en duda sus testimonios? ¿Quién sería capaz de afirmar que mienten? Los creadores de las grandes ficciones serían así los seres que sueñan por los demás los que por (desdichado) encargo de los dioses están destinados a revelar los misterios de la existencia ( 221-222).

Es evidente en este segmento la presencia de netos juicios de valor sobre la producción de los grandes artistas: lo que ellos han expresado, pese a ser "ficcion(es)", es "verdad", en tanto es conducente a la revelación de "misterios" (= lo trascendente). La importancia de lo irracional-personal esta dada por su

\footnotetext{
4 Es curioso observar cómo la crítica, por lo general, adopta el mismo tipo de registro (binario) que Sábato. Lo más común, es observar unaespecie de mimetismo discursivo por el cual el que reflexiona sobre la obra sabatiana, adopta las mismas categorías, sostiene los mismos juicios de valor, etc., que el escritor, sin llevar a cabo el análisis de este tipo de registro. Uno de los pocos trabajos que resalta la naturaleza dual de la producción de Sábato es el de Graciela Maturo, "La aventura filosofica de Ernesto Sábato", en Ernesto Sábato en la crisis de la modernidad (Buenos Aires: Fernando García Cambeiro, 1985), 13-34, sobre todo p. 16 (en que se compara el tipo de reflexión de Sábato a la de Octavio $\mathrm{Paz}$; véanse asimismo las p. 26 y 30 . Véanse, complementariamente, las reflexiones sobre los ensayos de Sábato hechas por David Lagmanovich, "Un ensayo de Ernesto Sábato: 'Sobre los dos Borges"', en Homenaje a Ernesto Sábato, ed. Helmy F. Giacoman (Madrid: Anaya-Las Américas, 1973), 273-293 y las de Angela B. Dellepiane en Ermesto Sabato. El hombre y su obra (New York: Las Américas, 1968), sobre todo las secciones dedicadas a los ensayos, 37-77 y 153-190.
} 
trascendencia en la esfera de lo “universal”. La dialéctica de extremos sigue funcionando aquí. Concluye Sábato afirmando que:

[D]e ahí la resonancia de su obra [la de Dante]. Los italianos que veían pasar al poeta (...), comentaban (...) con sagrado recelo y sin intención metaforica: “Ahr va el que estuvo en el Infierno". Porque si esos visionarios no fueran más que mitomanos individuales, si sus visiones no fueran más que delirios de estricto valor privado, ¿cómo explicar su trascendencia universal?, ¿y cómo explicar que el resto de los mortales los tomen como intérpretes de sus confusas angustias y esperanzas? ¿Cómo explicar, en fin, que la palabra vate signifique a la vez Poeta y Adivino? (222).

No es un secreto que la defensa de lo irrecional esté presente en la obra de Sábato (tanto en su labor narrativa como en sus ensayos) desde temprano ${ }^{5}$. De hecho, ese pensamiento hilvana todos sus escritos y constituye un núcleo fundamental que informa toda su producción literaria ${ }^{6}$. En ese sentido, sería permisible ubicar a ésta dentro de la tradición postromántica que tan productiva ha sido dentro de la literatura latinoamericana ${ }^{7}$. Sábato, de hecho, pertenece a la tradición de aquellos pensadores (novelistas, ensayistas, poetas) que

${ }^{5}$ Los ejemplos de esta actitud son numerosísimos tanto en el contexto de las novelas como el de los ensayos e incluso las cartas y discursos del escritor argentino. Ya desde Hombres y engranajes (con un título sumamente explícito), pasando por El escritory sus fantasmas,, Itinerario, Páginas de Ernesto Sabato, etc., es visible la constancia con que se vapulea la razón y se busca la unidad por medio del arte. Véase, por ejemplo, de que manera tan explícita lo hace Sábato en su carta incluida en el volumen Ernesto Sábato en la crisis ..., (9-12), especialmente 10-12. No es un accidente el que Sábato coloque al arte en un "reino intermedio ... entre el sueño y la realidad, entre lo inconciente y lo conciente, entre la sensibilidad y la inteligencia" (10-11), sobre todo luego de afirmar que en el (el arte) "se conjugan todas [las] ... facultades [de la criatura humana]" (10). Es decir, el arte es la vía a la unidad y la posibilidad de acceder a otra región superior ("intermedia"). La carta es de julio de 1979. La reflexión sobre el surrealismo en los textos de Sábato es sobremanera curiosa. Su desconfianza ante la escritura automática lo lleva de alguna manera a "racionalizar" el arte. Véase, por ej. la p. 140 de Uno y el universo (Barcelona: Seix Barral, 1981).

"Véase, por ejemplo, Trinidad Barrera, "Ernesto Sábato: lo mágico y lo logico", en Ernesto Sábato. Premio "Miguel de Cervantes" 1984 (Barcelona: Anthropos, 1988), 77-96, (especialmente 79-81); en el mismo volumen, véase asimismo Marina Galvez ( 23, 30, 40-41; también véase Carlos Catania, Sábato: Entre la idea y la sángre (San José, Costa Rica: Editorial Costa Rica, 1973), 48-49, 60-62, 70-81 (sobre todo, 137-140, sobre lo irracional en relación con el género novelístico, 179-180; Graciela Maturo, "La aventura filosofica ...", en Ernesto Sábato en la crisis ..., 13-34.

${ }^{7}$ Véase el ensayo de María Rosa Lojo, "La poética neorromántica de Ernesto Sábato", en Ernesto Sábato en la crisis ..., 175-202. Si bien se adopta aquí un registro un tanto mimético, es apreciable la seriedad -y variedad - de las fuentes bibliográficas consultadas en torno al problema. 
asumen para sí mismos la función de intérpretes de una cultura y de sus malestares. En este contexto, la oposición entre razón y no-razón parece haber sido más que decisiva; ha sido fundamental, de la misma manera que lo fue para los románticos anglosajones.

Ya desde El laberinto de la soledad de Octavio Paz y pasando, por supuesto, por el brillante y versátil El arco y la lira, Los signos en rotación y otros ensayos, la obra de un Cortázar (novelas y prosa ensayística), la temprana novela de Alejo Carpentier $-e$, incluso, sus ensayos anteriores y posteriores a Los pasos perdidos -, etc, la reflexión sobre y el privilegio de lo irracional (así, en terminos generales), ha sido una constante de una buena porción de las letras hispanoamericanas ${ }^{8}$. La conexión de los citados escritores y, por supuesto, Sábato, con el surrealismo no es casual.

En general, y cambiando lo que ha de cambiarse, el registro de pensamiento en el que se mueven estos textos es neo o postromántico. En ellos, la voz del poeta (narrador oensayista) se asume comola del creador (Dios-Adán): el hablante intenta dar origen a aquello que se refiere, y el referente, en términos generales, está planteado como aspiración (de ahí que la cuestión se retome una y otra vez). El instrumento privilegiado de conocimiento es el que provee la imaginacióninspiración (también bajo otros nombres), esto es, la(s) potencia(s) enigmática, intuitiva, unitiva. En casi todos los casos y con variantes, la literatura postromántica hace del Otro buscado el término de su discurso. Sea este Otro la mujer, la tierra (o ambos en conjunción), el lenguaje - y hay que notar que todos estos núcleos de reflexión están presentes en el ensayo sabatiano- 9 , o el tiempo, lo que se manifiesta en los textos es una tensión constante. Esta, o en otras palabras la dialéctica de extremos entre los cuales se realiza el discurso, es de tenor romántico; no en vano en todos los casos el lector se enfrenta con entidades dicotómicas, esto es, una pareja de términos, uno de los cuales debe ser eliminado o subsumido en el otro ${ }^{10}$.

\footnotetext{
${ }^{8}$ He reflexionado sobre este problema, inicialmente, en mi trabajo La fundación mitológica de América Latina (Madrid: Fundamentos, 1989); también en "Octavio Paz: la espiral y la línea o la reescritura del romanticismo" en Revista Iberoamericana 151 (abril-junio 1990):, 393-401; "Octavio Paz: Hispanoamérica o la metáfora como fundación", Iberoromania, 33 (primavera 1991), 140-144. Los lineamientos téricos del presente trabajo proceden de las reflexiones expuestas en mi $E l$ sueño del origen: la tradición postromántica (Madrid: Fundamentos, en prensa).

${ }^{\ominus}$ El caso de los ensayos sobre el tema femenino incluidos en el volumen Heterodoxia (luego recopilados en Itinerario), sería uno de los más claros.

${ }^{10}$ Este binarismo (junto con el esencialismo que conlleva) es una herencia que le llega al romanticismo por vía del neoplatonismo y de la tradición hermética. Sobre este aspecto y otros conexos, véase el minucioso y útil volumen de Meyer $\mathrm{H}$. Abrams, Natural $\mathbf{S u}$ pernaturalism. Tradition and Revolution in Romantic Literature (New York: W. W. Norton \& Company, Inc., 1973), 146-163. De manera espléndida, Abrams lleva a cabo un análisis de todos aquellos motivos, metáforas, etc., que eran ya tópicos en la tradición occidental. Una observación parecida (y cambiando lo que ha de cambiarse), puede
} 
No importa cuál sea el "asunto" sobre el que se escribe; la actitud ante el fenómeno literario es, con ligera diferencia de matices, en extremo semejante. Todo lleva al mismo problema de fondo: la necesidad de unir, de reconciliar(se), de paliar la escisión - la diferencia- El texto que se analiza aquí no es la excepción. En efecto, y como se ha mencionado, aparecen en él los mismos motivos conductores que se pueden advertir en el discurso de un Paz o del temprano Carpentier (o de un Cortázar) y que ya estaban presentes en la obra anterior ${ }^{11}$.

No es por ello extraño que el ensayo que nos ocupa haga de la nota personal su justificación en tanto comienzo. Si las "obsesiones" de que se habla son determinantes en la concepción de una "teoría" sobre el infierno, esas obsesiones (personales) tienen su razón de ser porque existe algo que comparten todos los artistas, los "poetas-adivinos". En otras palabras, se puede generalizar, esto es, elaborar una "teoria" a partir de experiencias personales ya que ellas han de ser comunes a los demás. La experiencia del uno debe ser válida para los otros, en un registro de tipo especular nada extraño al romanticismo y/o sus manifestaciones. En este tipo de contexto, lo individual se quiere como general $\mathrm{y}$, por tanto, trascendente. No en vano, está siempre presente en este tipo de escritura una nota de tipo mesiánico. El camino hacia lo Otro siempre pasa por (y lleva a) el mismo.

Por el otro lado, si lo que importa aquí es elaborar una teoría que, retomando el binomio razón/no-razón, legitime la posibilidad de conocimiento (profético, supraracional, etc), en última instancia, la posibilidad de salvación por la literatura, la pieza entonces se nos ofrece como otro de esos viajes iniciáticos característicos de la literatura de Sábato (y de los románticos). En este periplo, el sujeto realiza una suerte de inquisición (que es una búsqueda) a través de la cual trata de demostrar la verdad de sus aserciones. Pero el camino (el medio empleado) conduce, antes que nada, a reafirmar la propia subjetividad: las "obsesiones" personales (nota que sería también común a los artistas románticos) ${ }^{12}$. Volvemos al punto de partida. No hay progreso.

extrapolarse al caso de los escritores que se han mencionado. Respecto de la necesidad de subsumir un término en el otro (en la oposición de términos polares), véase la nota (5) y la cita correspondiente.

in Véanse las afirmaciones del mismo Sábato en el segundo párrafo de la Explicación (Prólogo a Itinerario (Buenos Aires: Sur, 1969), 7. Al respecto, véase Carlos Catania, Sábato: entre la idea ...: "Un novelista como Sábato escribe en realidad un solo libro, aunque haya publicado varios. Una única obsesión lo acosa en el fondo a través de toda su creación, representada en sus términos más amplios por la persistente melancolía de lo absoluto" (137). Véase asimismo Trinidad Barrera, ibid., 92 (sobre la presencia de constantes temáticas - "materiales" semejantes-en la obra del escritor argentino). El trabajo de María Rosa Lojo es de gran utilidad, asimismo, ya que en el se realiza un recuento de "afinidades" (186-187) y de "convergencias" (194-196).

12 Véase, por ejemplo, el comentario del propio Sábato en su Advertencia a la edición de 1945 de Uno y el universo, ed. cit., p. 15: "(Uno se embarca hacia tierras lejanas, o busca el conocimiento de hombres, o indaga la naturaleza, o busca a Dios; después se advierte que el fantasma que se perseguía era Unomismo)". La cita es tan explícita como el título de la obra. 
El cambio implicaría, por el contrario, no tanto la solidez de una solución, sino el "final" -el acabamiento - de la literatura y/o del arte. El salto a la convergencia llevaría al silencio, la cancelación de la escritura. Aquí en cambio, la alabanza de lo irracional nos devuelve al principio, esto es, a la persona del artista que, en este caso, es Sábato mismo: el producto de este ejercicio se actualiza como necesidad de seguir escribiendo. Las consecuencias retóricas no son menos importantes.

De alguna manera, el ensayo ofrece el terreno discursivo adecuado para el enmascaramiento de un sujeto, que es narrador y a la vez personaje de la inquisición que pretende realizar. No en vano (y esto ya es un lugar común de la crítica), los personajes de Sábato reproducen las inquisiciones del autor a partir de los segmentos más disquisitivos de sus novelas. Sábato, en tanto artista (depositario de las facultades de loirracional) es el verdadero protagonista de la pieza, no el infierno. Si hay reaparición (repetición) en lo que se refiere a lo individual (= el sujeto) en su obra, el mismo fenómeno ocurre también en la esfera de lo que el sujeto trata de dilucidar. Como ya se ha mencionado antes, la recurrencia de los mismos motivos es característica y definitoria de la literatura tal como la practica Sábato.

La pregunta que aquí nos interesa no es tanto el cómo sino el por qué de esa recurrencia. De hecho, es posible interrogarse acerca de las consecuencias teóricas que este hecho tiene en conexión con la problemática del postromanticismo. ¿Por qué la repetitividad, o la obsesión, en todo caso? No es mi propósito reiterar nuevamente lo que la crítica (y Sábato mismo) han afirmado tantas veces, esto es, la escritura como catarsis de obsesiones, etc. (aunque ello sea cierto desde otro ángulo). De hecho, incluso la misma palabra "obsesion(es)" está presente en el ensayo aquí analizado. La idea, antes bien, es tratar de contextualizar este tipo de recurrencia dentro del marco de referencia del pensamiento postromántico, un pensamiento que es repetitivo porque la solución, por vía de la literatura, no puede hacerse presente. En otras palabras, la reiteración de lo mismo, llamese búsqueda de la unidad, de la reconciliación, etc., en las novelas, en los ensayos, cartas, entrevistas, sólo parece conducir a la reiteración. Podría especularse que lo que yace en el fondo es una cuestión de deseo y, por lo tanto, de repetición, de inacabamiento.

Si para Borges, "el estilo del deseo es la eternidad" ${ }^{\text {"13 }}$, es posible constatar que su actitud ante el fenómeno literario es muy diferente. Acaso no tan paradójicamente, sea esta literatura la que materializa el reino de aquello conjetural, enigmático que Sábato busca y que, de acuerdo con sus palabras, está lejano de los dominios de la razón y de la ciencia ${ }^{14}$. Así, lo que tenemos en

\footnotetext{
${ }^{13}$ Jorge L. Borges, "Historia de la eternidad", en Historia de la eternidad, Obras completas (Buenos Aires: Emece, 1974), 365.

${ }_{14}$ Ernesto Sábato, Uno y el universo, ed. cit., 16 (en la Advertencia a la edición de 1945 antes mencionada): "[R]eivindico el mérito de abandonar esa clara ciudad de las torres -donde reinan la seguridad y el orden-en busca de un continente lleno de peligros, donde domina la conjetura". El prólogo para la edición de 1968 atenúa algunos de los énfasis de esta advertencia y de los ensayos del volumen, sobre todo, desde el punto de vista ideologico.
} 
el Libro del cieloy del infierno, no es la reflexión sobre el cielo que nos merecemos y/o que hemos perdido (mutatis mutandis, el "high argument" de los románticos); no es tampoco una teoría sobre la necesidad de usar el instrumento literario para acceder al paraiso (surrealista o no). En otras palabras, no se lleva a cabo una antología de versiones para desprender de ellas un sistema de coincidencias, convergencias; no hay interpretación que lleve al momento sólido de la definición y sus consecuencias. No se busca una llave para edificar una taxonomía.

Por el contrario, la antología citada (que se puede muy bien leer en cualquier "orden"), no privilegia un texto por encima de los otros, en otras palabras, no destaca el valor de una opinión por oposición a otra ${ }^{15}$. Todo lo que tenemos son opiniones, "palabras" -como en "El inmortal"16 -, en última instancia, ficciones. Loque se repite es el gesto de releer y se relee, no solamente porque cambie el contexto. La reescritura/relectura de los textos dentro de la antologia también se hace para mostrar oblicua -y pérfidamente- que simplemente siempre se repite el mismo deseo de reconciliación.

El reino de la antologia, en este sentido, es el de la reescritura paródica del mito. Un mito que no tiene nada de trascendente, sino que no hace sino develar una nostalgia de origenes, un esfuerzo - racional o no- de desentrañar el más allá y que, como tal (en tanto deseo), engendra la repetitividad ${ }^{17}$. La antología repite perversamente la repetición; tantos textos sobre el cielo y el infierno acaban por anular su validez, terminan por cancelar el "orden" que se pretende encontrar (eimponer) sobre una realidad huraña, ajen ${ }^{18}$. Loque queda solamente

${ }^{16}$ El Libro del cieloy del infierno acoge una increíble cantidad y diversidad de piezas; sus "fuentes" (pretextos) son de índole diversa aunque puedan agruparse bajo el denominador común de "ficciones" sobre el cielo/infierno. Para un análisis textual más detallado sobre este problema, véase mi Cervantes y Borges: la inversión de los signos (Madrid: Pliegos, 1987), especialmente la seccion, "El antologizador", 137-144.

${ }^{16}$ La cita corresponde a Jorge L. Borges, "El inmortal”, en El Aleph, ibid., 544.

${ }^{17}$ En lo que se refiere a la reflexión sobre el mito, que es otra constante en la producción de Sábato, véase la carta antes citada (en Ernesto Sábato en la crisis ..., 11); también, véase el "Discurso de Ernesto Sábato en la entrega del Premio Cervantes 1984", citado más adelante. Es evidente que, por lo general, su interpretación de lo mítico pasa por lo trascendente. En lo que concierne a la repetitividad, es interesante confrontar alguna reflexión de Sábato respecto de la obra de Borges. Véase, por ejemplo, la pieza "Borges" en la ed. cit. de Uno y el universo, 20-24. Sábato que, de alguna manera, le reprocha a Borges la falta de elementos "humanos" en sus ficciones (22), advierte la presencia de la repetición (21). Lo que no puede ver con claridad es su razón textual de ser, su voluntaria intrascendencia. De ahí que se pregunte al final: “ ¿No estarán condenados a algún Infierno los que descreen? (24).

${ }_{18}$ Una de las tantas paradojas (y de alli el interés) del romanticismo es su iconoclasia respecto de todo orden $y$, por supuesto, la necesidad de inventar (o redescubrir) un nuevo orden que sea más humano, trascendente, etc., que el presente. Lo que se manifiesta aquí, por supuesto, es la cuestión apocalíptica del romanticismo tan bien examinada por M. H. Abrams en el volumen citado, Natural Supernaturalism., sobre todo,. 37-46, 329-356, 375-399. 
es la puesta entre paréntesis de los textos, su reinscripción en tanto avatares del mito. No en vano, y desde otro ángulo, esta reescritura es una transformación: los textos han cambiado. Pero el producto de la antologia (= el cambio) es textual, no trascendente. Si lo que se buscaba (en los pretextos), era llegar a la convergencia, el gesto de la reescritura anula toda aspiración "romántica" o pseudoromántica, cancela el deseo de convergencia entre lo real y lo textual. Todo comienza y acaba en el texto: sólo hay palabras.

Nada más lejano a esta práctica literaria que el esfuerzo de un Sábato. Con un optimismo en las antŕpodas del agnosticismo de Borges, con una fe en el destino humano que no cesó ni en los más tenebrosos momentos de su historia $-\mathrm{y}$ de la historia argentina-Sábato quiere la redención por la literatura. Y en ella, lo que rescatará al hombre de todas sus fallas, de la escisión (real) de la razón, es lo que lo conecta con el reino enigmático de lo alógico. En este sentido, la literatura (en especial la novela), se entiende como la "conjunción" de arte y de filosofía; el artista-poeta es el filósofo; su voz, el receptáculo de este conocimiento. No en vano se habla, en el ensayo "Sobre la existencia del infierno", de "teoria" (217).

En 1984, al recibir el Premio de Literatura en Lengua Castellana "Miguel de Cervantes", Sábato vuelve a expresarse en términos parecidos a los ya comentados $^{19}$. Su discurso pronunciado en la entrega del premio, reitera la conocida oposición entre términos polares: sueño y conceptualización, realidad e ilusiones, etc. Si bien el registro del texto sigue siendo de tipo binario y trascendentalista:

Esta caracteristica de las grandes ficciones es, precisamente, la que las convierte en grandes verdades. De un sueño se puede decir cualquier cosa, menos que sea una mentira. (...) Mediante aquello que desde antiguo se llamo inspiracion, sin proponérselo, el escritor rescata de ese territorio arcaico símbolos y mitos que confieren verdad a sus creaciones y que les daran la perdurabilidad de la especie humana. El espíritu puro [= la razón] produce ideas, pero las ideas cambian(...). Los sueños no progresan: dan verdades inmutables y absolutas. ( 58-59)

hay gran lucidez en el planteo; la perspectiva se ha ampliado. En principio, podríamos incluso coincidir con la idea de la "inmutabilidad" de los sueños (=los mitos), algo que ya aparecía en otra clave en la pieza "Sobre la existencia del infierno". Pero es esta misma inmutabilidad la que vendría a confirmar su repetitividad, y ésta, incluso su calidad de "verdaderos", aunque sólo por razones opuestas a las que Sábato enuncia: los sueños-mitos no son verdaderos per se; su "verdad" es la de la repetición. Lo que sigue más adelante parece confirmarlo:

\footnotetext{
${ }^{19}$ Véase el "Discurso de Ernesto Sábato en la entrega del Premio Cervantes 1984", en el volumen citado Ernesto Sábato ..., ed. cit., 55-61.
} 
Su verdadera patria [la del ser humano], a la que retorna después de sus periplos ideales [racionales], es esa región intermedia del alma, región en que amamos y sufrimos, porque el alma es prisionera de su cuerpo y el cuerpo es lo que nos hace "seres para la muerte". Es alli, en el alma, donde se aparecen los fantasmas del sueño y de la ficción. Los hombres construyen penosamente sus inexplicables fantasías porque están encarnados, porque ansían la eternidad y deben morir, porque desean la perfeccion y son imperfectos, porque anhelan la pureza y son corruptibles. Por eso escriben ficciones. Un dios no necesita escribirlas (60-61).

Una cuestión de deseo, nuevamente, un caro deseo de eternidad. Al situar la reflexión en el plano de la temporalidad, la pieza de Sábato cobra densidad y rigor. Las ficciones no son inmutables esencialmente, no son claves - ni viasde acceso a otra región superior, a la trascendencia. Son manifestaciones de una inmutable sí, pese a todo, temporalidad; son respuestas del hombre a una vana repetitividad que sólo cesa con la muerte. Los poetas, el vate "Poeta y Adivino" (con mayúscula) de la pieza que se analiza inicialmente ${ }^{20}$, son entonces los interpretes de este deseo de eternidad: no de la eternidad, sino de la conciencia de la temporalidad, la ironía paciana que siempre corroe a la analogía ${ }^{21}$. Aquí parece desgarrarse asimismo el planteo trascendentalista de Sábato: la interpretación nolleva a la definición; la voz del poeta no es la de Dios; si lo fuera, no necesitaría de sus sueños-mitos-ficciones. Así lo expresa también en un diálogo $0^{22}$ :

[E]l arte existe porque somos imperfectos. Escribimos porque buscamos la perfección, el Absoluto que no tenemos. Dios no necesita escribir novelas, pero nosotros s1, porque somos infinitamente imperfectos( 72).

No se trata de verdades, sino de fabulaciones. Es en este sentido, que el vate de Sábato parece acercarse cada vez más al hacedor borgiano. Al hacer suya la temporalidad de todos los hombres, Sábato acabaría por concretar uno de sus deseos: la de emitir un juicio que cobre validez general (aunque no trascendencia). La lucidez más evidente de estas reflexiones nos ubica en un terreno de límites antes que de aspiraciones: el ámbito de de los hombres y no de los dioses, la implacable ironía que siempre desgarra a la sagrada religión de la analogia. Como para Alejo Carpentier a partir de Los pasos perdidos, el reino del arte no es el de las conjunciones/revelaciones sino el del tiempo de los hombres, el de las ficciones elaboradas sobre el cielo/el infierno.

\footnotetext{
${ }^{20}$ En la página ya citada (222) del ensayo "Sobre la existencia del infierno", de la ed. cit.

${ }^{21}$ Véase Octavio Paz, Los hijos del limo (Barcelona: Seix Barral, 1981), 91-114.

${ }^{22}$ Véase Mónica Liberman, Luis García Martín, Arnoldo Liberman, "Conversación con Ernesto Sábato", en Ernesto Sábato ..., ed. cit., 63-76.
} 